\title{
INFLUENCE OF ARNICA FOLIOSA NUTT. DRY EXTRACT ON THE GENERATIVE FUNCTION OF RATS
}

\author{
A.N. Babenko, L.V. Krepkova, S.V. Lemyaseva \\ FSBSI All-Russian research institute of medicinal and aromatic plants, \\ 117216, Russia, Moscow, Grina str., b.1.
}

DOI: 10.19163/MedChemRussia2021-2021-287

E-mail: babenko@vilarnii.ru

Despite the wide arsenal of anti-inflammatory drugs on the modern pharmaceutical market, the problem of developing and implementing new effective and low-toxic herbal medicines is urgent. One of such promising plants for the creation of medicines of this activity on its basis is Arnica foliosa Nutt. In the VILAR, a dry extract of Arnica foliosa Nutt. (DEAF) was obtained from its aerial parts, the chemical composition of which is mainly represented by phenolic compounds that make up 30-35\% (flavonoid glycosides, phenol-carboxylic acids). The aim of our study was to study the effect of DEAF on the generative function of male and female rats when it was administered intragastrically for 60 and 15 days, respectively, at doses of 250,1250 and $2500 \mathrm{mg} / \mathrm{kg}$ before mating with intact animals.

The administration of DEAF in the tested doses to rats of both sexes before mating with intact animals did not reduce the ability of males to fertilize and females to conceive. DEAF did not cause an increase in pre-and post-implantation death rates compared to the control group. Pregnant females obtained after mating rats injected with the test extract with intact animals gave birth to healthy rat pups. The number of newborns in the litter and their body weight in all experimental groups did not differ significantly, and the survival index for 21 days of their postnatal development was $100 \%$. The physical development of the rats of all experimental groups was the same and corresponded to the physiological standards.

The results obtained made it possible to create rectal suppositories based on Arnica foliosa Nutt. 0,05 g, cream 1,5\% and gel $1 \%$ for external use, intended for local conservative treatment of inflammatory diseases [1].

\section{References}

[1] V. V. Bortnikova, L. V. Krepkova, N. S. Mikheeva, M. V. Borovkova, Preclinical study of the safety of Arnica foliosa Nutt. dry extract, Experimental and clinical pharmacology. 2019, Volume 82, No. 5, pp. 28-35. 